\title{
Adherence to glatiramer acetate treatment for multiple sclerosis: the Brazilian experience
}

\author{
Tatiana de Melo Gomes \\ de Oliveira' \\ Ana Patricia Peres Fiore ${ }^{2}$ \\ Yára Dadalti Fragoso ${ }^{2}$ \\ 'TEVA Pharmaceutical, Brazil; ${ }^{2}$ Medical \\ School of Universidade Metropolitana \\ de Santos and Reference Center \\ for Multiple Sclerosis of the coastal \\ region of the State of São Paulo \\ (DRS-IV), Brazil
}

\begin{abstract}
Multiple sclerosis is a chronic disease characterized by demyelination and neurodegeneration of the central nervous system. Immunomodulatory treatment is possible at an early stage of the disease, and consists of injections of either beta-interferon or glatiramer acetate. The drugs are not curative, and the need for frequent injections may give rise to a serious problem regarding adherence to treatment. The present study analyzed the database of all Brazilian patients using glatiramer acetate between June 2003 and December 2006 who had enrolled in the patient program run by the pharmaceutical company commercializing the drug. The rate of treatment discontinuation was $10 \%$ over this period, and the main reason for suspending the drug was medical decisions ( $47 \%$ of all discontinuations), rather than side effects or the patient's choice. The present work did not take into consideration the regularity of injections and the main objective was to assess discontinuation. It was concluded that adequate healthcare, education, and a specific program for patients were the factors responsible for this $90 \%$ adherence to glatiramer acetate treatment in Brazil.
\end{abstract}

Keywords: multiple sclerosis, glatiramer acetate, adherence

\section{Introduction}

Multiple sclerosis (MS) is a chronic disease of the central nervous system (CNS). Although inflammation and demyelination are the pathological hallmark of MS, the associated neurodegeneration leads to neurological sequelae, which makes MS the second greatest cause of neurological disability among young adults, surpassed only by trauma.

The most typical and frequent presentation of the disease is the remitting-relapsing form, characterized by bouts of neurological signs and symptoms lasting from a few weeks to a few months and longer periods of clinical remission. Despite decades of intense research on the causes of and cures for MS, there are still vast knowledge gaps regarding this condition.

Apart from symptomatic treatment that should be proposed for all patients with MS, some patients also qualify for immunomodulatory and/or immunosuppressive treatment. These qualifying patients are those at the early, mainly inflammatory phase of the disease, when relapses are still frequent and are related to T1-lymphocytes and other immunological cells targeting the CNS. The immunomodulatory treatment at this stage may be performed by means of either beta-interferon (IFN $\beta$ ) in three different formulations, or glatiramer acetate (GA). All of these treatments are in the form of injections: IFN $\beta$ subcutaneously or intramuscularly, and GA subcutaneously. More recently, monoclonal antibodies have been introduced as a possible form of treatment, but drugs at present approved in most countries are still IFN $\beta$ and GA. These medications, many of which have the possibility for self-injection, have a variety of side effects, including reactions at the injection site among those used subcutaneously. It is important to emphasize that these drugs must be used over a very long period of 
time, and their effect is to reduce the frequency of relapses, which is not always an easy target to assess from the point of view of the patients, who may have much higher expectations from MS treatment.

Patient adherence to such treatments needs to be carefully assessed. According to the World Health Organization (2003), adherence is defined as the extent to which the behavior of an individual undergoing treatment really corresponds to the recommendations given by the healthcare professional. A variety of factors may influence adherence in MS cases, and a list of such factors, far from complete, is presented in Table 1. Few studies have been performed to assess the reasons for withdrawing from treatment with IFN $\beta$ (Hadjimichael and Vollmer 1999; Tremlett and Orger 2003; Rio et al 2005) and even fewer in relation to GA (Fraser et al 2001).

The first 6 months of treatment seem to be crucial for proper adherence (Tremlett and Orger 2003), and side effects during this period appear to be the main reason for withdrawal of injections (O'Rourke and Hutchinson 2005). Starting therapy in very disabled patients also seems to lead to higher degrees of non-adherence (Rio et al 2005). Healthcare support for patients has been rated as an important factor in adherence, particularly for patients who were already switching between immunomodulatory drugs (Fraser et al 2001).

The aim of the present study was to assess the level of adherence and discontinuation of therapy with GA among Brazilian patients who have had access to a special program developed by TEVA Pharmaceutical specifically for Brazil. Unlike the programs proposed by TEVA and other

Table I Possible factors influencing adherence to immunomodulatory treatment for multiple sclerosis

\begin{tabular}{ll}
\hline Reasons for not adhering & Patient's justification \\
\hline Long periods of remission & Idea of being cured \\
Injections & Fear or discomfort with needles \\
Occurrence or fear of side effects & $\begin{array}{l}\text { Previous experience or } \\
\text { information from other patients }\end{array}$ \\
Hopelessness and resignation & Idea of a disease without cure \\
Lack of motivation and/or & Reasons for treatment were not \\
knowledge & explained \\
Unmet expectations from & Lack of improvement of sequelae \\
treatment & or new relapse \\
Search for other forms of & Influence from family and friends \\
treatment & \\
$\begin{array}{l}\text { Several consultations searching for } \\
\text { another diagnosis and denial of the } \\
\text { disease }\end{array}$ & $\begin{array}{l}\text { Conflicting information from } \\
\text { health care providers }\end{array}$
\end{tabular}

pharmaceutical companies in other countries, the Brazilian program does not consider patients to be at "high" or "low" risk of discontinuation and, once enrolled in the personal assistance program, all patients receive the same care.

The Brazilian Federal and State governments provide the drugs freely to all patients with MS who require immunomodulatory treatment. Patients who receive a diagnosis of MS are referred to the closest university reference center for investigation and treatment of the disease, with a prescription for a particular immunomodulatory drug given by the neurologist accompanying the case. Should the reference center confirm the diagnosis and the precise indication for this prescription, the patient will receive the medication monthly, free of any charge. In the MS Reference Center for the coastal region of the State of São Paulo (Fragoso and Fiore 2005), all patients learn directly from the nurse how to perform the injections. The nurse also provides them with her personal telephone numbers for any contact that patients deem necessary.

To clarify the mechanism of action for GA, which requires daily injections, and also to describe how the TEVA adherence program works once Brazilian patients start on GA, a short summary of these two topics is detailed below.

\section{Glatiramer acetate (Copaxone ${ }^{\circledR}$, TEVA Pharmaceutical, Israel)}

GA was developed in the 1960s, as a standard mixture of synthetic polypeptides with four amino acids: L-alanine, L-glutamine, L-lysine and L-tyrosine. The drug was discovered during an attempt to isolate the antigen responsible for experimental allergic encephalomyelitis (EAE), which is the animal model for MS (Wolinsky 1995). It turned out that GA was not capable of inducing EAE and, furthermore, had a suppressive effect on the animal disease. Several clinical trials with long-term follow-up have shown that GA is an effective treatment for MS (Ford et al 2006). The mechanism of action for GA is unique among the drugs at present approved for MS treatment: rather than having any specific and direct anti-inflammatory effect through inhibition of Th-1 lymphocytes, GA promotes a shift to an anti-inflammatory environment by activating Th-2 lymphocytes (Young 2002). Maintenance of this anti-inflammatory shift is obtained by daily subcutaneous injections of GA.

Among the adverse reactions with GA, the most frequent are redness, itching, pain, and swelling at the injection site. These reactions are usually mild and seldom require professional treatment. Some patients report a short-term reaction immediately after injecting GA. 
This reaction may involve flushes, chest tightness or pain, tachycardia, or breathing trouble. These symptoms generally appear within minutes of an injection, are short-lived and go away by themselves without further problems. Despite the short duration, the so-called immediate postreaction can be very distressing for patients. However, full awareness among patients that such a reaction is possible seems to decrease discontinuation if the reaction occurs (Fiore and Fragoso 2005). Severe skin reactions to GA injections have recently been reported in some patients (Frohman et al 2004). Although infrequent, such skin reactions (including lipoatrophy, necrosis, and erythema nodosum) are severe enough to require discontinuation of GA treatment (Frohman et al 2004; Thouvenot et al 2007).

\section{PACO - The Assistance Program for Copaxone ${ }^{\circledR}$}

This assistance program was created in June 2003, and every Brazilian patient with a medical prescription for Copaxone $^{\circledR}$ can enroll via a free phone call to the central PACO system, in TEVA Pharmaceutical, São Paulo. In the initial phone call, the patient is registered in the program and receives detailed information about the medication, including: storage, transportation, the importance of adherence, possible side effects, alternative injection sites, and special guidance to avoid local reactions at the injection site.

The patient receives at home, free of any charge, an insulated bag for carrying the medication, a written guide and DVD on how to perform the injections, a box for used needles and syringes, a gel bag for soothing the area where the injection is made, the Autoject ${ }^{\circledR}$ (Owen Munford Ltd., Oxford, England) self-applicator, and printed material regarding MS.

All patients will thereafter receive a phone call every fortnight for 90 days and every 3 months after this initial 90-day period. Extra phone calls from PACO nurses and from the patients to the central system are made as deemed necessary (for example, in cases of side effects). Visits by nurses to patients' homes can be organized if necessary. The patients are also regularly reminded about the importance of attending medical consultations with their neurologist.

Workshops on a variety of subjects (for example, nutrition, art and crafts, etc) are regularly organized in different cities in Brazil.

Nurses working at reference centers for MS can be specifically trained through PACO to attend to the needs of patients living in the area covered by that particular MS service.

\section{Methods}

Data from all Brazilian patients enrolled in the PACO program between June 2003 and December 2006 were assessed. Their registration included gender, age and educational level attained. Data on discontinuation of GA treatment were obtained for the period from January 2006 to December 2006. All patients discontinuing treatment with GA gave their own reasons for stopping taking the medication, and there was no record of medical reasons in PACO for such discontinuation. This program is directed towards patients, and medical doctors do not contact it unless they specifically want to do so.

Statistical data were analyzed by the Software Minitab $14^{\circledR}$, using chi-square and relative risk for assessment of treatment interruption. Significance level was established as $\mathrm{p}<0.05$.

\section{Results}

A total of 1131 patients were fully registered within the program between June 2003 and December 2006. The demographic characteristics of these patients are presented in Table 2. In summary, there were 289 males (26\%) and 842 females (74\%), aged between 9 and 79 years.

A total of 113 patients (10\%) stopped their treatment with GA, for a variety of reasons that are detailed in Table 3. Eight patients were excluded from the data because they died during the study period.

The main reason for stopping the treatment was medical advice (53 cases; $47 \%$ of the total number of stopped treatments). No information was given on possible switching of therapy to another immunomodulatory agent, since PACO does not record either the medical reports on patient care or the follow-up for patients who are not taking GA. A group of

Table 2 Demographic characteristics of patients undergoing treatment for multiple sclerosis with glatiramer acetate in Brazil

\begin{tabular}{lll}
\hline Gender & Number of patients & Percentage of total \\
\hline Male & 289 & $26 \%$ \\
Female & 842 & $74 \%$ \\
Age group (years) & & \\
$9-20$ & 85 & $8 \%$ \\
$21-30$ & 220 & $19 \%$ \\
$31-40$ & 333 & $29 \%$ \\
$41-50$ & 288 & $25 \%$ \\
$51-60$ & 168 & $15 \%$ \\
$61-70$ & 34 & $3 \%$ \\
$70-79$ & 3 & $<1 \%$ \\
\hline
\end{tabular}


Table 3 Number of patients discontinuing treatment with glatiramer acetate and their motives for this interruption

\begin{tabular}{|c|c|c|c|}
\hline $\begin{array}{l}\text { Reason for discon- } \\
\text { tinuation of treat- } \\
\text { ment }\end{array}$ & $\begin{array}{l}\text { Number of } \\
\text { patients }\end{array}$ & $\begin{array}{l}\text { Percentage of } \\
\text { the number of } \\
\text { patients who } \\
\text { interrupted } \\
(n=113)\end{array}$ & $\begin{array}{l}\text { Percentage of } \\
\text { total number } \\
\text { of patients } \\
(n=|| 3 \mid)\end{array}$ \\
\hline Medical conduct & 53 & $47 \%$ & $5 \%$ \\
\hline Patient's own choice & 20 & $18 \%$ & $2 \%$ \\
\hline $\begin{array}{l}\text { Non-serious adverse } \\
\text { event }\end{array}$ & 18 & $16 \%$ & $2 \%$ \\
\hline $\begin{array}{l}\text { Immediate reaction } \\
\text { post-injection }\end{array}$ & 9 & $8 \%$ & $<1 \%$ \\
\hline $\begin{array}{l}\text { Reaction in the site of } \\
\text { injection }\end{array}$ & & $7 \%$ & $<1 \%$ \\
\hline Pregnancy & 4 & $4 \%$ & $<1 \%$ \\
\hline $\begin{array}{l}\text { Hematopoietic stem } \\
\text { cell transplantation }\end{array}$ & I & $1 \%$ & $<1 \%$ \\
\hline
\end{tabular}

20 patients (18\% of all the discontinuations) explained that ceasing to take GA was their own decision, mainly because they did not perceive any improvement with this treatment. A group of 35 patients ( $31 \%$ of all the discontinuations) stopped taking GA due to adverse events, none of them recorded as serious. Among this group who stopped taking GA due to adverse events, 9 patients mentioned systemic reactions immediately after the injection, and 8 patients could not tolerate the reactions at the injection site. The remaining 18 patients mentioned a variety of symptoms that might or might not have been related to GA, since some of them appeared to be related to MS itself (for example, fatigue).

There was no correlation between gender, age, years of formal education, and stopping the treatment (Table 4). The largest single group of patients who stopped their treatment did so after receiving between 6 and 12 months of GA therapy
( $27 \%$ of the discontinuations for that period of treatment). Relative risk assessment showed a 3.42 times higher chance of interrupting treatment in this period of 6-12 months of GA treatment, as shown in Table 5.

\section{Discussion}

Adherence to treatment among MS cases is a challenge for all healthcare providers. This is a chronic and disabling disease, for which no cause and/or cure are known. Despite encouraging results with immunomodulatory treatment, the main goal of this therapy is to delay disability in patients who still respond to this immunological approach. The simple knowledge that the treatment is not curative and consists of injections with a variety of side effects may discourage patients from persisting with the treatment. A large survey among neurologists treating over $2500 \mathrm{MS}$ patients showed that "forgetting to take the injection" was the main reason for non-adherence to treatment (Devonshire et al 2006). The present work did not deal with the matter of non-adherence to the occasional injection but, rather, took discontinuation of treatment to be the main objective of this investigation.

The medical reasons for stopping the treatment, which were the main motive for discontinuation of GA among Brazilian patients, cannot be discussed here because PACO does not record such information. A smaller, but still considerable percentage of the patients stopped their treatment because of personal reasons, and most discontinuations occurred soon after the frequency of the phone call program had gone down to 1 call every 3 months. Education for patients and caregivers is essential for them to understand the need to comply with the scheme for the proposed medication, as well as for them to have realistic expectations from the treatment. As shown earlier, in Table 1, most reasons for stopping the treatment were related to the lack of proper knowledge about the disease and

Table 4 Period of treatment with glatiramer acetate between June 2003 and December 2006, and discontinuations of therapy; the only significant $p$ value was observed for the period 6-12 months of glatiramer acetate therapy

\begin{tabular}{lllll}
\hline $\begin{array}{l}\text { Period of } \\
\text { use }\end{array}$ & $\begin{array}{l}\text { Total number of } \\
\text { patients }(\mathbf{n}=\mathbf{I} \text { |3I) }\end{array}$ & $\begin{array}{l}\text { Percentage of total } \\
\text { number of patients }\end{array}$ & $\begin{array}{l}\text { Number of patients who interrupted } \\
\text { treatment }(\mathbf{n}=1 \mathbf{1 3})\end{array}$ & $\begin{array}{l}\text { Percentage of patients in that period } \\
\text { who interrupted treatment }\end{array}$ \\
\hline $\begin{array}{l}\text { Up to } 6 \\
\text { months }\end{array}$ & 233 & $21 \%$ & 22 & $9 \%$ \\
6 to 12 & 131 & $12 \%$ & 35 & $27 \%(\mathrm{p}<0.001)$ \\
months & & $15 \%$ & 23 & $14 \%$ \\
One year & 167 & $29 \%$ & 23 & $7 \%$ \\
Two years & 330 & $21 \%$ & 10 & $4 \%$ \\
Three years & 236 & $3 \%$ & - & - \\
Four years & 34 & & &
\end{tabular}


Table 5 Demographic characteristics of multiple sclerosis patients who interrupted glatiramer acetate treatment

\begin{tabular}{llll}
\hline Parameter & $\begin{array}{l}\text { Total number of patients } \\
\text { in the group }\end{array}$ & $\begin{array}{l}\text { Number of patients who interrupted } \\
\text { treatment in that group }\end{array}$ & $\begin{array}{l}\text { Percentage of patients who interrupted } \\
\text { treatment in that group }\end{array}$ \\
\hline $\begin{array}{l}\text { Gender } \\
\text { Male }\end{array}$ & 289 & $8 \%$ \\
Female & 842 & 91 & $11 \%$ \\
Age group (years) & & & $11 \%$ \\
$9-20$ & 85 & 9 & $10 \%$ \\
$21-30$ & 220 & 21 & $10 \%$ \\
$31-40$ & 333 & 33 & $10 \%$ \\
$41-50$ & 288 & 29 & $12 \%$ \\
$51-60$ & 168 & 20 & $3 \%$ \\
$61-70$ & 34 & 1 & - \\
$>70$ & 3 & - & \\
\hline
\end{tabular}

the excessive expectations. All pharmaceutical companies that are currently commercializing immunomodulatory drugs for MS typically provide a specific support program for patients taking their drugs. These programs are aimed at the needs of specific countries with different cultures, socioeconomic backgrounds and educational levels.

Based upon previous experience with early discontinuation of immunomodulatory treatment, typically within 6 months of starting (Tremlett and Orger 2003), most programs for patients appear to concentrate their efforts in this initial period. The US Copaxone ${ }^{\circledR}$ program, with a lower number of phone calls, has recently reported high rates of discontinuations of GA treatment within 3 months of starting the injections (Parker and Beach 2006, 2007). The approach in the US program has been to attempt to identify "high risk" patients and concentrate the efforts on this group. The results from the present study showed that discontinuation was most likely to occur over a longer period of 6-12 months, when the number of phone calls to patients had decreased. No gender, years of schooling, or age-related groups at risk were identified, and therefore it was not possible to consider that a particular subgroup of patients is at "higher" or "lower" risk. Based on the results obtained here, the PACO program for MS patients in Brazil is now considering an increased number of phone calls and visits for all patients, during the whole first year of treatment.

The profiles of the side effects of IFN $\beta$ (O'Rourke and Hutchinson 2005) and GA (Parker and Beach 2006, 2007) are reported to be an important reason for early discontinuation of treatment. Again, this was not observed in the present study with GA, in which only $4 \%$ of the whole group of patients discontinued their treatment because of side effects.
Healthcare support for patients has been rated as an important factor for adherence to GA treatment (Fraser et al 2001), and it is possible that the low levels of discontinuation in Brazil are related to this special program. In addition, the personal and special attention given to every case by a multidisciplinary team, which is typical of the university reference centers, may also be reflected in the high rate (90\%) of adherence to long-term treatment with GA.

\section{Acknowledgments}

The PACO program acknowledges the important help provided by the trainee nurses Mirtes Oliveira and Amanda Fernandes.

\section{Disclosures}

Ana Patricia Peres Fiore and Yára Dadalti Fragoso are independent university researchers and have not received (and will not receive) any form of payment for the present work.

Publication fees for this paper were unconditionally paid by TEVA Pharmaceutical.

\section{References}

Devonshire V, Lapierre Y, MacDonell R, et al. 2006. The Global Adherence Project - a multicentre observational study on adherence to diseasemodifying therapies in patients suffering from relapsing-remitting multiple sclerosis [abstract]. Presented at: 22nd Congress of the European Committee for Treatment and Research in Multiple Sclerosis (ECTRIMS); September 27-30, 2006; Madrid, Spain.

Fiore APP, Fragoso YD. 2005. Tolerability, adverse events and compliance to glatiramer acetate in 28 patients with multiple sclerosis using the drug continuously for at least six months. Arq Neuropsiquiatr, 63:738-40.

Ford CC, Johnson RP, Lisak RP, et al, and the Copaxone Study Group. 2006. A prospective open-label study of glatiramer acetate: over a decade of continuous use in multiple sclerosis patients. Mult Scler, 12:309-20. 
Fragoso YD, Fiore APP. 2005. Description and characteristics of 81 patients attending the Reference Center for Multiple Sclerosis of the coastal region of the state of Sao Paulo-Brazil. Arq Neuropsiquiatr, 63:741-4.

Fraser C, Hadjimichael O, Vollmer T. 2001. Predictors of adherence to Copaxone therapy in individuals with relapsing-remitting multiple sclerosis. J Neurosci Nurs, 33:231-9.

Frohman E, Brannon K, Alexander S, et al. 2004. Disease modifying agent related skin reactions in multiple sclerosis: prevention, assessment, and management. Mult Scler, 10:302-7.

Hadjimichael O, Vollmer TL. 1999. Adherence to injection therapy in MS: Patient survey. Neurology, 52(Supp1 2):A549.

Rio J, Porcel J, Tellez N, et al. 2005. Factors related with treatment adherence to interferon $\mathrm{b}$ and glatiramer acetate therapy in multiple sclerosis. Mult Scler, 11:306-9.

O'Rourke KE, Hutchinson M. 2005. Stopping beta-interferon therapy in multiple sclerosis: an analysis of stopping patterns. Mult Scler, 11:46-50.

Parker D, Beach B. 2006. Improving adherence and compliance: 90 days high risk compliance call questions. Personal communication 2006, Global Seminar on Nurse and Patient Education; 30th-31st January, Lucerne, Switzerland; and Annual Meeting May 30th -June 2nd, 2007 Washington DC, Consortium of Multiple Sclerosis Centers - Poster S56.
Rovaris M, Comi G, Rocca M, et al, and European/Canadian Glatiramer Acetate Study Group. 2007. Long-term follow-up of patients treated with glatiramer acetate: a multicentre, multinational extension of the European/Canadian double-blind, placebo-controlled, MRI monitored trial. Mult Scler, 13:502-8

Thouvenot E, Hillaire-Buys D, Bos-Thompson MA, et al. 2007. Erythema nodosum and glatiramer acetate treatment in relapsing-remitting multiple sclerosis. Mult Scler, 13:941-4.

Tremlett HL, Orger J. 2003. Stopping and switching of the $ß$-interferons prescribed for MS. Neurology, 61:551-4.

Wolinsky JS. 1995. Copolymer 1: a most reasonable alternative therapy for early relapsing remitting multiple sclerosis with mild disability. Neurology, 45:1245-7.

World Health Organization. 2003. Adherence to long term therapies: evidence for action. Geneva: World Health Organization. Chapter I, section I.

Young V. 2002. Differential mechanisms of action of interferon- $\beta$ and glatiramer acetate in MS. Neurology, 59:802-8. 